\section{Substance misuse during pregnancy}

\author{
K. JOHNSON, C. GERADA and A. GREENOUGH
}

The use of illicit substances such as cocaine and heroin during pregnancy is common. Anonymous screening of consecutive urine samples testing positive for pregnancy from a UK inner-city clinic demonstrated that approximately $16 \%$ of the women had taken one or more illicit substances (Sherwood et al, 1999). The prevalence of drug misuse in the USA appears to be even higher: prospective screening of newborns in a high-risk urban population revealed that $44 \%$ of 3010 babies tested positive for opiates, cocaine or cannabis (Ostrea et al, 1992). The aim of this editorial is to emphasise the importance of this topic by describing the unfavourable effects illicit substances can have on both pregnancy and infant outcome. In addition, discussion of the evidence base for current management highlights the need for appropriately designed studies to optimise treatment and reduce morbidity.

\section{PREGNANCY OUTCOME}

Pregnancy complications, including premature rupture of the membranes, meconiumstained liquor and foetal distress, are more common in women who misuse drugs (Ostrea et al, 1992). Cocaine has been associated with placental abruption, particularly if taken around the time of delivery, and opiates increase the likelihood of antepartum haemorrhage (Hulse et al, 1998). Meta-analysis of the results of six studies demonstrated that the odds ratio for antepartum haemorrhage in women using opiates was 2.33 (95\% CI 1.324.30), but the studies did not adjust for possible confounders such as antenatal care and cocaine or tobacco use, which might account for some of the observed effect (Hulse et al, 1998). Antenatal care is often inadequate in women who misuse drugs because of late presentation; reasons for this include a chaotic lifestyle and a reluctance to have involvement with social services. Prematurity and intrauterine growth retardation have been associated with illicit drug use in pregnancy (Gillogley et al, 1990), even after controlling for smoking, antenatal care and prior preterm births. Meta-analysis of studies examining neonatal outcome revealed that, compared with healthy controls, the mean reductions in birthweight associated with drug misuse were $489 \mathrm{~g}$ for heroin, $279 \mathrm{~g}$ for methadone and $557 \mathrm{~g}$ for the combined use of heroin and methadone (Hulse et al, 1997). Reductions in birthweight and head circumference appear most marked in infants of women taking cocaine or of those who are multiple drug misusers (Gillogley et al, 1990). The majority of women misusing drugs during pregnancy use cannabis only (Sherwood et al, 1999), but this also has been associated with a significantly lower gestational age at birth and a reduction in birthweight (Sherwood et al, 1999). Benzodiazepine misuse during pregnancy has been reported to cause dysmorphic features in the infant resembling the foetal alcohol syndrome, growth aberrations and central nervous system anomalies (Laegreid et al, 1989), and cocaine misuse has been linked to sudden infant death (Kandall \& Gaines, 1991).

\section{INFANT OUTCOME}

\section{Neonatal abstinence syndrome}

Neonatal abstinence syndrome or withdrawal symptoms occur in $55-94 \%$ of neonates exposed to opiates in utero (American Academy of Pediatrics Committee on Drugs, 1998). Commonly seen symptoms include irritability, high-pitched cry, tremors, hypertonicity, vomiting, diarrhoea and tachypnoea. Hyperphagia also occurs, usually associated with weight loss, but occasionally with excessive weight gain (Shephard et al, 2002). Methadone, compared with heroin, causes more severe and more prolonged withdrawal (Chasnoff et al, 1990). A strong relationship has been reported between the maternal methadone dose at delivery and severity of neonatal withdrawal as assessed by the Neonatal Abstinence Score, length of stay and duration of treatment (Malpas et al, 1995). As a consequence, careful reduction of the maternal methadone dosage during pregnancy is recommended; low maintenance doses, however, are continued to try to prevent illicit drug use. Methadone has a high oral bioavailability, unlike most opioids; it has a long duration of action and less misuse potential. Multiple drug misuse alters the pattern of withdrawal: for example, maternal cocaine use is associated with a reduction in the severity of opioid withdrawal by inducing a reduction in the adrenergic activity of the neurons of the locus coeruleus, but it does have vasoconstrictive effects on the developing brain, leading to neurological abnormalities and neonatal convulsions.

\section{Growth and development}

Infants of women taking opiates, particularly the synthetic opioid methadone, have a two to three times increased risk of unexplained sudden death in infancy (Davidson Ward et al, 1990); this may be due to abnormal respiratory control. Studies examining growth are frequently difficult to interpret, because of high attrition rates and the compounding social factors which might militate against normal growth patterns (Vance et al, 1997). The growth pattern during the first 12 months, however, does appear to reflect the intrauterine growth retardation suffered by drug-exposed infants. In one series (Vance et al, 1997) some catch-up growth was demonstrated, but persistent weight retardation at age 12 months correlated with methadone usage during pregnancy, although this was not corrected for social status (Vance et al, 1997). Developmental outcome may be impaired in infants of women who misuse drugs, as indicated by the wide variety of mild cognitive effects in pre-school children reported by researchers using the Bayley scales of mental development (Gauthier et al, 1999). Children born to women maintained on methadone have been suggested to be more likely to show poor development, further compounded by factors associated with drug misuse such as smoking, alcohol misuse, and poor nutrition, housing and education (Johnson et al, 1990). Examination of 
children aged 36 months, however, highlighted that some children appear to be resistant to the effects of maternal drug use, as they had developed appropriately (Johnson et al, 1990).

\section{MANAGEMENT DURING PREGNANCY}

To improve pregnancy outcome it is important to engage pregnant women early. Some drug services have therefore set up clinics jointly with antenatal services and also liaise with labour wards.

\section{Screening}

Improving the outcome of drug misuse during pregnancy requires accurate identification of affected women and their infants; this cannot be achieved by maternal interview alone (Ostrea et al, 1992). In one series (Gillogley et al, 1990), $40 \%$ of women who denied substance misuse had positive urine tests for non-prescribed substances. Urine screening of the mother or infant, however, has a high rate of false negative results, as it is dependent on the time of sampling related to the time that has elapsed since the mother last misused drugs (Ostrea et al, 1992). The most accurate screening method is analysis of meconium, but this is not undertaken routinely in the UK. Drug metabolites accumulate in meconium by direct deposition from bile or by ingestion of metabolites in the amniotic fluid (or both). Meconium is not usually excreted antenatally and accumulates throughout gestation, thus its composition reflects not only recent drug use (Ostrea et al, 1992).

\section{Substitution therapy}

The overall aim of antenatal treatment varies according to the type of drug being misused. If the woman is taking cocaine then the aim should be to reduce - ideally stop - its intake. Substitution therapy is appropriate for those misusing opiates as otherwise relapse is likely, which can result in cycling between withdrawal to intoxication, with wide variations in opiate levels and resulting foetal stress (Fischer et al, 2000). It is also generally better to keep pregnant women on maintenance treatment, rather than to insist on abstinence and risk losing them from contact (Department of Health, 1999). Substitution therapy is usually methadone which, compared with the illicit use of heroin, is associated with greater access of antenatal care and hence better maternal and infant outcomes, including a reduced risk of preterm delivery and low birth weight (Jarvis \& Schnoll, 1995). Neonatal abstinence syndrome, however, may be more common in infants whose mothers took methadone rather than heroin (Chasnoff et al, 1990), being reported in $60-80 \%$ of newborns exposed to methadone in utero. As a consequence, other maintenance treatments have been explored, including the opiate partial agonist buprenorphine. In one study (Fischer et al, 2000) no adverse effect on mother or foetus with buprenorphine was demonstrated and few of the infants required treatment for neonatal abstinence syndrome, but only 15 women and their offspring were examined. Buprenorphine, however, does not have a specific licence to be used in pregnancy and it tends to block the action of other opioid agonists, so it could interfere with opioid analgesics given for pain relief.

\section{TREATMENT OF NEONATAL ABSTINENCE SYNDROME - HOSPITAL OR COMMUNITY?}

Approximately half of infants suffering from neonatal abstinence syndrome require pharmacological treatment. A variety of agents, including morphine, methadone, chlorpromazine, phenobarbitone and diazepam, have been administered with the aim of controlling withdrawal symptoms (Johnson et al, 2003). Despite the large numbers of infants requiring treatment for the syndrome, few agents have been examined in randomised trials with long-term outcome measures (Johnson et al, 2003). Affected infants can require treatment for many months, leading to a prolonged stay on the neonatal unit (Coghlan et al, 1999). This has a major impact not only on maternal and infant bonding, but also on bed occupancy. In one institution in Dublin, at any one time three neonatal beds were always occupied by infants with neonatal abstinence syndrome (Coghlan et al, 1999). A proportion of such infants require neonatal care because of problems not directly related to their drug withdrawal, such as prematurity, but the duration of stay and associated hospital costs can be reduced for infants who are otherwise 'healthy' by discharging them home once they are stable on treatment. A concern regarding such an approach, however, is that parents who misuse drugs may not have sufficiently competent organisational skills to comply with the out-patient follow-up schedule required by infants with medical needs. Indeed, only half of women who were misusing drugs kept their infants' out-patient appointments in one survey. It has been suggested that compliance with clinical attendance can be improved (Oei et al, 2001), but this requires establishment of a hospital-based weekly follow-up clinic with continuity of care provided by staff with whom the families have become familiar and which meets all the infants' needs, including vaccinations, subspecialist appointments and prescriptions for the treatment of neonatal abstinence syndrome. In the UK, the general practitioner and the baby's health visitor are important in maintaining continuity of care and can be useful for monitoring treatment in the baby and mother. Whichever follow-up package is adopted, community care for infants with neonatal abstinence syndrome and ongoing treatment needs must be adequately resourced. Whether such management, compared with prolonged hospital admission, is more cost-effective in improving the long-term outcome of affected infants requires appropriate testing.

\section{DECLARATION OF INTEREST}

None.

\section{ACKNOWLEDGEMENTS}

Dr Johnson is supported by Action on Addiction. We thank Ms Sue Williams for secretarial support.

\section{REFERENCES}

American Academy of Pediatrics Committee on Drugs (1998) Neonatal drug withdrawal. Pediatrics, 10I, 1079-1088.

Chasnoff, I. J., Landress, H. J. \& Barrett, M. E. (1990) The prevalence of illicit-drug use during pregnancy and discrepancies in mandatory reporting in Pinellas County, Florida. New England Journal of Medicine, 322 1202-1206.

Coghlan, D., Milner, M., Clarke, T., et al (1999) Neonatal abstinence syndrome. Irish Medical Journal, 92. 232-233.

Davidson Ward, S. L., Bautisa, D., Chan, L., et al (1990) Sudden infant death syndrome in infants of drug abusing mothers. Journal of Pediatrics, II7, 876-887.

Department of Health (1999) Drug Misuse and Dependence - Guidelines on Clinical Management. London: Stationery Office. 
Fischer, G. W., Johnson, R. E., Eder, H., et al (2000) Treatment of opioid-dependent pregnant women with buprenorphine. Addiction, 95, 239-244.

Gauthier, S. M., Bauer, C. R., Masinger, D. S., et al (1999) The Bayley scales of infant development. II: Where to start. Journal of Behavioural Pediatrics, 20. 75-79.

Gillogley, K. M., Evans, A. T., Hansen, R. L., et al (1990) The perinatal impact of cocaine, amphetamine, and opiate use detected by universal intrapartum screening. American Journal of Obstetrics and Gynecology 163, 1535-1542.

Hulse, G. K., Milne, E., English, D. R., et al (1997)

The relationship between maternal use of heroin and methadone and infant birth weight. Addiction, 92 , |57|-1579.

$\ldots, \ldots, \ldots$, et al (1998) Assessing the relationship between maternal opiate use and antepartum haemorrhage. Addiction, 93, I553-1558.

Jarvis, M. A. E., \& Schnoll, S. H. (1995) Methadone use in pregnancy. NIDA Research Monograph, $\mathbf{1 4 9}$, $58-77$.

Johnson, H. L., Glassman, M. B., Fiks, K. B., et al (1990) Resilient children: individual differences in developmental outcome of children born to drug abusers. Journal of Genetic Psychology, I5I, 523-539.

Johnson, K., Gerada, C. \& Greenough, A. (2003) Treatment of neonatal abstinence syndrome. Archives of Disease in Childhood, 88, F2-5.

K. JOHNSON, MRCPCH, King's College Hospital; C. GERADA, FRCGP, Hurley Clinic, London; A. GREENOUGH, MD, King's College Hospital, London, UK

Correspondence: Professor Anne Greenough, Department of Child Health, King's College Hospital London SE5 9RS, UK. Tel: 0207346 3037; fax: 0207924 9365; e-mail: anne.greenough@kcl.ac.uk

(First received 19 June 2002, final revision 18 December 2002, accepted 18 December 2002)

Kandall, S. R. \& Gaines, J. (1991) Maternal substance use and subsequent sudden infant death syndrome (SIDS) in offspring. Neurotoxicology and Teratology, $\mathbf{1 3}$ $235-240$

Laegreid, L., Olegard, R., Walstrom, J. N. C. (1989) Teratogenic effects of benzodiazepine use during pregnancy. Journal of Pediatrics, II4, I26-131.

Malpas, P. J., Darlow, B. A., Lennoz, R., et al (1995) Maternal methadone dosage and neonatal withdrawal. Australia and New Zealand Journal of Obstetrics and Gynecology, 35, 175-177.

Oei, J., Feller, J. M. \& Lui, K. (200I) Coordinated outpatient care of the narcotic-dependent infant. Journal of Paediatrics and Child Health, 37, 266-270.

Ostrea, E. M., Brady. M., Gause, S., et al (1992) Drug screening of newborns by meconium analysis: a large-scale, prospective, epidemiologic study. Pediatrics. 89, I07-II3.

Shephard, R., Greenough, A., Johnson, K., et al (2002) Hyperphagia, weight gain and neonatal drug withdrawal. Acta Paediatrica, 9I, 95I-953.

Sherwood, R. A., Keating, J., Kavvadia, V. et al (1999) Substance misuse in early pregnancy and relationship to fetal outcome. European Journal of Pediatrics, 158 488-492.

Vance, J. C., Chant, D. C., Tudehope, D. I., et al (1997) Infants born to narcotic dependent mothers: physical growth patterns in the first 12 months of life. Journal of Paediatrics and Child Health, 33, 504-508. 